\title{
A headspace solid-phase microextraction method of use in monitoring hexanal and pentane during storage: Application to liquid infant foods and powdered infant formulas
}

\author{
Guadalupe García-Llatas a , María Jesús Lagarda ${ }^{a}$, Fernando Romero b, \\ Pedro Abellán ${ }^{\mathrm{b}}$, Rosaura Farré ${ }^{\text {a,* }}$ \\ ${ }^{a}$ Faculty of Pharmacy, Nutrition and Food Chemistry, University of Valencia, Avda. Vicent Andrés Estellés s/n, 46100 Burjassot, Spain \\ ${ }^{\mathrm{b}}$ Hero España S.A., Quality and Development Department, Avda. Murcia, Alcantarilla, Murcia, Spain
}

Received 25 October 2005; received in revised form 20 February 2006; accepted 4 March 2006

\begin{abstract}
The determination of two secondary lipid oxidation compounds (hexanal and pentane) in liquid infant foods using a headspace solidphase microextraction gas chromatographic (HS-SPME-GC) method has been developed and validated.

The HS-SPME analytical conditions (fibre position, equilibration and sampling times) were selected. The analytical parameters of the method (linearity: hexanal from 2.48 to $84.78 \mathrm{ng} / \mathrm{g}$, pentane from 6.21 to $79.55 \mathrm{ng} / \mathrm{g}$; precision: hexanal - 2.87\%, pentane - 2.34-3.46\%; recovery: hexanal $-106.60 \%$, pentane $-95.39 \%$; detection limit: hexanal $-3.63 \mathrm{ng}$ and pentane $-4.2 \mathrm{ng}$ ) demonstrate the usefulness of the method.

Once optimized, the method was applied to liquid infant foods based on milk and cereals, and to powdered adapted and follow-up milk-based infant formulas (IF), stored for four and seven months. In all cases the hexanal content was higher in IF than in milk-cereal based infant foods. No pentane was found in IF.
\end{abstract}

(c) 2006 Elsevier Ltd. All rights reserved.

Keywords: Hexanal; Pentane; Liquid infant foods; HS-SPME-GC determination; Lipid oxidation

\section{Introduction}

Oxidative degradation due to auto oxidation of polyunsaturated fatty acids, present in variable amounts in most foods, is one of the well recognized factors that may limit the shelf-life of lipid containing foods, due to the loss of food quality through flavour deterioration, a decrease in nutritional value and the generation of potentially toxic substances that can have a significant impact on food safety (Fenaille, Visani, Fumeaux, Milo, \& Guy, 2003; Goodridge, Beaudry, Pestka, \& Smith, 2003; Park \& Goins, 1992; Sanches-Silva, Rodríguez-Bernaldo de Quirós, López-Hernández, \& Paseiro-Losada, 2004). Indi-

\footnotetext{
* Corresponding author. Tel.: +34 963544 950; fax: +34963544954. E-mail address: rosaura.farre@uv.es (R. Farré).
}

cators of lipid oxidation state are therefore of great interest for controlling the quality of fat-containing products.

The primary oxidation products for unsaturated fatty acids are the hydroperoxides - highly reactive compounds that decompose rapidly, yielding a complex mixture of non-volatile and volatile compounds such as hydrocarbons (ethane, pentane), aldehydes (pentanal, hexanal, hexenal, 2-octenal, 2-nonenal) and ketones, which affect the overall quality of the product. Aldehydes are particularly important in relation to flavour alteration and from a toxicological perspective (Frankel, 1980, 1982, 1993).

The lipid fraction of infant foods contains a relatively large amount of unsaturated fatty acids, together with non-negligible amounts of minerals, including iron, can enhance lipid oxidation. Linoleic acid is abundant in infant products fat, and yields 9- and 13-hydroperoxide that decomposes to produce pentane and hexanal, among 
others, as secondary oxidation volatile compounds (Frankel, Neff, \& Weisleder, 1982).

Extended storage, without daylight, of infant formulas resulted in high concentrations of propanal, pentanal, hexanal, heptanal and nonanal (Romeu-Nadal, Castellote, \& López-Sabater, 2004; Ulberth \& Roubicek, 1995). However, the major product of fat oxidation that increases in content during storage is hexanal. This has become a known indicator of fat oxidation (Brunton, Cronin, Monahan, \& Durcan, 2000). Hexanal content is directly related to oxidative off-flavours, and the compound is easily detected because of its low odour threshold (5 ppb) (Buttery, Turnbaugh, \& Ling, 1988). However, hexanal has the potential to react further, and it is not always possible to measure the compound directly.

Pentane content can also increase during storage as a consequence of oxidative lipid degradation, and this compound has also been proposed as an indicator of fat oxidation. Pentane content correlates very well to sensory evaluation, and it is useful for monitoring the oxidation of fats during storage. Compared to hexanal, pentane offers the advantage of being inert and stable under adequate storage conditions (Löliger, 1990).

Different methods have been proposed for determining the volatile compounds originated during lipid oxidation. Although direct injection of the lipid fraction into a gas chromatograph (GC) has been used (Dupuy et al., 1985; Snyder, Frankel, Selke, \& Warner, 1988), different sampling techniques have been described to isolate and concentrate volatile compounds prior to GC injection - including solid phase extraction (SPE), simultaneous steam distillation, liquid extraction and headspace (HS) analysis. Headspace analysis, alone or combined with SPE, remains a widely used procedure, because it requires only minimal sample treatment - thereby reducing artifactual volatile compound formation. Different approaches have been described, such as static headspace gas chromatography (SHGC) and dynamic headspace gas chromatography (DHGC). In this context, a SHGC method has recently been developed for determining volatile compounds in infant formulas (Romeu-Nadal et al., 2004).

Solid-phase microextraction (SPME) makes use of a fibre that adsorbs analytes from samples. Usually, equilibrium between the matrix and the stationary phase coating the fibre is reached. SPME integrates sampling, extraction, concentration, and sample introduction to GC. It offers high through-put performance and does not require extended sample preparations - thus resulting in time savings. Moreover, it is reproducible, simple and effective, and eliminates much interference from the sample matrix, with improvement in selectivity of the analysis. In addition, the technique is inexpensive, and avoids the use of solvents for extraction (Arthur \& Pawliszyn, 1990; Zhang, Yang, \& Pawliszyn, 1994).

Techniques combining HS with SPME (HS-SPME) have been used to study the volatile profiles of different foods and drinks (Gianelli, Flores, \& Toldrá, 2002; Dolesc- hall, Recseg, Kemény, \& Kövári, 2003; Jelen, Wlazly, Wasowicz, \& Kaminsky, 1998), including the identification of saturated aldehydes as the main volatile agents present in the headspace of infant milk powders (Fenaille et al., 2003; Przygonski, 2003). The stationary phase coating the fibre and the extraction conditions must be selected for each specific analyte and type of sample (Marsili, 1999; Vichi, Pizzale, Conte, Buxaderas, \& López-Tamames, 2003).

Liquid, ready-to-eat, cereal and milk based infant foods recently have been marketed, and it is of interest to monitor the stability of their lipid fraction over time.

The present study develops and validates an HS-SPMEGC method for determining pentane and hexanal in liquid milk-cereal based infant foods, that is useful in monitoring the stability of the lipid fraction during storage of the products. The possibility of applying it to different milk powdered infant formulas (IF) is also evaluated.

\section{Materials and methods}

\subsection{Samples}

Taking into account that hexanal and pentane can be formed during storage as a consequence of lipid oxidation, and with the purpose of assessing the usefulness of the method set up for determining hexanal and pentane in infant foods, the following samples were collected:

- Two liquid infant foods (LH and LF) based on milk $(88 \%)$ and cereals $(8.8 \%)$ with $2.6 \%(\mathrm{w} / \mathrm{w})$ fat $(3.1 \mathrm{~g} /$ $100 \mathrm{ml})$ and differing in a minor ingredient: LH contained honey $(0.9 \%)$ and LF fruits $(1.1 \%)$. These products were supplied by the manufacturer (Hero España S.A.), and were analyzed after 4 and 7 storage months.

- Four powdered infant formulas (IF): two adapted (A and Alc) (the latter containing fish oil to provide long chain polyunsaturated fatty acids) and two follow-up formulas $(\mathrm{Fa}$ and $\mathrm{Fb})$ were used. From each IF two samples corresponding to two different manufacturing batches and storage times ( 4 and 7 storage months) were sampled. The fat contents $(w / w)$ of the IF were: A (29\%); Alc (27.5\%); $\mathrm{Fa}$ and $\mathrm{Fb}(25 \%)$.

All the products were maintained in their original sealed containers in an atmosphere free of air until analysis.

The fatty acid profiles of the samples, determined by GC-FID as fatty acid methyl ester (FAME) and applying the conditions previously reported (Lagarda, Máñez, Manglano, \& Farré, 2003), are presented in Table 1. The composition in fatty acids is given as percentages of the total fatty acid content.

\subsection{Reagents}

Hexanal (Sigma; Steinheim, Germany); methanol p.a. (Merck; Darmstadt, Germany); pentane (Aldrich; 
Table 1

Fatty acid profile of the samples expressed as percentage of total fatty acids (mean values \pm standard deviation)

\begin{tabular}{|c|c|c|c|c|c|}
\hline \multirow[t]{2}{*}{ Fatty acids } & \multicolumn{5}{|l|}{ Samples } \\
\hline & LH and LF & A & Alc & $\mathrm{Fa}$ & $\mathrm{Fb}$ \\
\hline Caproic & $0.08 \pm 0.01$ & $0.11 \pm 0.01$ & $0.21 \pm 0.09$ & $0.03 \pm 0.05$ & $0.09 \pm 0.02$ \\
\hline Caprylic & $0.92 \pm 0.05$ & $1.25 \pm 0.15$ & $0.95 \pm 0.31$ & $1.04 \pm 0.10$ & $1.07 \pm 0.16$ \\
\hline Capric & $0.82 \pm 0.02$ & $1.08 \pm 0.05$ & $1.37 \pm 0.08$ & $0.99 \pm 0.17$ & $1.32 \pm 0.20$ \\
\hline Lauric & $8.11 \pm 0.51$ & $9.98 \pm 0.57$ & $10.15 \pm 1.72$ & $10.43 \pm 0.38$ & $11.09 \pm 0.89$ \\
\hline Myristic & $4.52 \pm 0.10$ & $4.74 \pm 0.10$ & $5.88 \pm 0.23$ & $4.87 \pm 0.02$ & $5.06 \pm 0.10$ \\
\hline Palmitic & $19.00 \pm 0.05$ & $20.94 \pm 0.15$ & $22.58 \pm 0.30$ & $21.96 \pm 0.22$ & $20.41 \pm 0.12$ \\
\hline Palmitoleic & $0.11 \pm 0.00$ & $0.12 \pm 0.01$ & $0.40 \pm 0.04$ & $0.15 \pm 0.04$ & $0.15 \pm 0.01$ \\
\hline Stearic & $4.05 \pm 0.11$ & $4.35 \pm 0.42$ & $5.76 \pm 0.39$ & $4.49 \pm 0.15$ & $4.35 \pm 0.38$ \\
\hline Oleic & $40.33 \pm 0.39$ & $40.04 \pm 0.70$ & $36.49 \pm 1.16$ & $39.54 \pm 0.63$ & $39.04 \pm 0.75$ \\
\hline Linoleic & $18.58 \pm 0.18$ & $15.07 \pm 0.25$ & $13.42 \pm 0.38$ & $13.69 \pm 0.14$ & $14.97 \pm 0.33$ \\
\hline Arachidic & $0.28 \pm 0.00$ & $0.32 \pm 0.01$ & $0.29 \pm 0.02$ & $0.32 \pm 0.02$ & $0.33 \pm 0.01$ \\
\hline$\gamma$-Linolenic & $0.09 \pm 0.01$ & $0.13 \pm 0.00$ & $0.12 \pm 0.01$ & $0.19 \pm 0.01$ & $0.13 \pm 0.01$ \\
\hline$\alpha$-Linolenic & $1.19 \pm 0.01$ & $0.91 \pm 0.04$ & $0.85 \pm 0.03$ & $0.91 \pm 0.01$ & $0.97 \pm 0.03$ \\
\hline Behenic & $0.35 \pm 0.01$ & $0.31 \pm 0.00$ & $0.29 \pm 0.02$ & $0.30 \pm 0.02$ & $0.33 \pm 0.01$ \\
\hline Arachidonic & n.d. & n.d. & $0.09 \pm 0.01$ & n.d. & n.d. \\
\hline EPA & $0.14 \pm 0.01$ & $0.12 \pm 0.01$ & $0.11 \pm 0.01$ & $0.11 \pm 0.01$ & $0.13 \pm 0.01$ \\
\hline DHA & n.d. & n.d. & $0.20 \pm 0.01$ & n.d. & n.d. \\
\hline
\end{tabular}

LH, liquid infant food with honey; LF, liquid infant food with fruits; A, adapted infant formula; Alc, adapted infant formula with long chain polyunsaturated fatty acids added; Fa and Fb, follow-up infant formulas; EPA, cis-5,8,11,14,17-eicosapentaenoic acid; DHA, cis-4,7,10,13,16,19-docosahexaenoic acid; n.d., not detectable.

Steinheim, Germany); 4-methyl-2-pentanone (MIBK) used as internal standard (IS) (Fluka; Buchs, Switzerland); Millipore MilliQ deionised water (Millipore Ibérica S.A., Barcelona, Spain).

\section{3. $H S-S P M E$ procedure}

Approximately $4 \mathrm{~g}$ of sample (liquid infant food) and a micro-stirring bar (length $12 \mathrm{~mm}$; $\varnothing 4 \mathrm{~mm}$; Bibby; Staffordshire, UK) were introduced in a 10-ml headspace amber glass vial (height $45 \mathrm{~mm}$; $\varnothing 20 \mathrm{~mm}$ ) that was immediately crimped with an aluminium seal containing a silicone-lined/PTFE septum (both from Supelco; Bellefonte, PA). Three $\mu \mathrm{l}$ of a methanol solution containing $80 \mu \mathrm{g}$ MIBK $/ \mathrm{ml}$ was added through the septum with a $10-\mu 1$ syringe (SGE; Ringwood, Australia). MIBK was the IS used with the same SPME fibre by Marsili (1999) in the analysis of whole and skimmed milk - a matrix constituting the main ingredient in our samples.

To keep the temperature $\left(37^{\circ} \mathrm{C}\right)$ constant during analysis, the vials were maintained in a water bath on a stirringheating plate (IKA; Staufen, Germany) and stirred at high speed during the equilibration and extraction periods, to achieve faster equilibrium. A temperature of $37^{\circ} \mathrm{C}$ was selected, because higher temperatures could alter the matrix composition and promote hydroperoxide decomposition, while temperatures below $37^{\circ} \mathrm{C}$ would not favour analyte release to the headspace and could not prevent variations in the conditions of the assay related to changes in the temperature of the laboratory (Frankel, Hu, \& Tappel, 1989; Robards, Kerr, Patsalides, \& Korth, 1988).

At the end of the equilibration period, a conditioned $\left(2 \mathrm{~h}\right.$ at $\left.300{ }^{\circ} \mathrm{C}\right) 85 \mu \mathrm{m}$ Carboxen ${ }^{\mathrm{TM}} /$ polydimethylsiloxane (CAR/PDMS) StableFlex ${ }^{\mathrm{TM}}$ fibre (Supelco; Bellefonte,
PA) was exposed to the headspace of the sample for analyte extraction - adjusting the SPME holder assembly to 1.0 scale units to ensure that the fibre was identically positioned from run to run. The CAR/PDMS fibre is especially sensitive to small molecules, and was selected on the basis of the specifications of the SPME manufacturer and literature reports on hexanal determination (Chung, Partridge, \& Harte, 2002; Doleschall, Kemény, Recseg, \& Kovári, 2001; Marsili, 1999; Marsili, 2000; Vichi et al., 2003). Following adsorption, the fibre was immediately thermally desorbed in the $\mathrm{GC}$ injector at $250^{\circ} \mathrm{C}$ for $5 \mathrm{~min}$ (splitless mode for $1 \mathrm{~min}$ ), to prevent carry-over from run to run.

\subsection{Gas chromatographic-flame ionization detector ( $G C$ - FID) conditions}

An Autosystem XL ${ }^{\mathrm{TM}}$ Perkin-Elmer GC (Norwalk, CT) equipped with a FID and an Equity $5^{\mathrm{TM}} 5 \%$ diphenyl $/ 95 \%$ dimethylsiloxane capillary column $(30 \mathrm{~m} \times 0.53 \mathrm{~mm} ; 5 \mu \mathrm{m}$ film thickness; Supelco; Bellefonte, PA) was used. As the diameter of the injection liner used can affect peak width, especially for early-eluting compounds (Yang \& Peppard, 1994), a narrow 1-mm i.d. direct liner (Supelco; Bellefonte, PA) was used. The chromatographic conditions were previously selected: hydrogen was the carrier gas, at a flow rate of $2.1 \mathrm{ml} / \mathrm{min}$; the temperature of the oven was initially $40^{\circ} \mathrm{C}$ for $5 \mathrm{~min}$, and was increased to $100^{\circ} \mathrm{C}$ at a rate of $4{ }^{\circ} \mathrm{C} / \mathrm{min}$, then to $220^{\circ} \mathrm{C}$ at $17^{\circ} \mathrm{C} / \mathrm{min}$, and finally held at $220^{\circ} \mathrm{C}$ for $10 \mathrm{~min}-$ yielding a total run time of $37 \mathrm{~min}$. The FID temperature was $300^{\circ} \mathrm{C}$. The response was monitored with Totalchrom ${ }^{\mathrm{TM}}$ workstation software (PerkinElmer; Norwalk, CT).

Carry over and peaks originating from the fibre were regularly assessed by running blank samples (water). 
2.5. Gas chromatographic-mass spectrometry ( $G C-M S)$ conditions

To confirm the presence of pentane and hexanal in the samples a GC-MS analysis was carried out. Samples were treated as described in the HS-SPME procedure. The SPME holder was adjusted at 3 scale units and inserted for $5 \mathrm{~min}$ (splitless mode for $1 \mathrm{~min}$ ) into the injector (at $250{ }^{\circ} \mathrm{C}$ ) of an Agilent $6890 \mathrm{~N} \mathrm{GC}$ equipped with an Agilent 5973N mass-selective detector (Palo Alto, CA). The stationary phase was a ZB- $5 \mathrm{~ms}$ capillary column $(5 \%$ polysilarylene $/ 95 \%$ polydimethylsiloxane; $30 \mathrm{~m} \times 0.32 \mathrm{~mm} ; 1 \mu \mathrm{m}$ film thickness; Phenomenex ${ }^{\circledR}$; Torrance, CA). The temperature program was the same that in GC-FID; the ion source temperature was $230{ }^{\circ} \mathrm{C}$; and helium was the carrier gas operated at a constant flow of $3.1 \mathrm{ml} / \mathrm{min}$. The mass spectrometer operated in the electron impact (EI) ionization mode at $70 \mathrm{eV}$, and mass spectral data were acquired in the mass range of 29-300 amu. Scan and selected ion monitoring (SIM) were used as data acquisition mode, the ions chosen being 56 and 72 for hexanal and 57 and 72 for pentane. Identification of the compounds was carried out by comparing their spectra with those of the Wiley library.

\subsection{Application}

The method was applied to the infant foods described in the sample section. Samples were in their fourth and seventh storage months. Powdered samples were reconstituted at $0.5 \%(\mathrm{w} / \mathrm{v})$ with Millipore MilliQ deionised water for analysis.

\section{Results and discussion}

\subsection{Method optimization}

Specificity, sensitivity and time required for the analysis were the factors taken into account in selecting the analytical conditions (fibre position and equilibration and sampling times) for hexanal and pentane determination in liquid infant foods. In the optimization of the method a LH sample was used.

\subsubsection{Fibre position in the GC injection port}

The fibre was exposed for $45 \mathrm{~min}$ to the headspace of a spiked sample (41.72 $\mathrm{ng}$ hexanal $/ \mathrm{ml}$ ) previously equilibrated for $15 \mathrm{~min}$ at $37^{\circ} \mathrm{C}$, and then inserted in the injection port for $5 \mathrm{~min}$ at different positions $(4,4.2$ and 4.4 scale units) of the SPME holder, with running of the GC oven program.

Following initial desorption, the fibre was desorbed a second time, since analyte carry-over affects quantitation and requires additional desorptions before the next sampling is carried out. The value of the second desorption was used to estimate the percentage of hexanal desorption $(\% D)$ corresponding to the first injection, which was calculated as follows: \% $D=\left(A_{1} \times 100\right) /\left(A_{1}+A_{2}\right)$, where
$A_{1}=$ hexanal area in the first desorption, and $A_{2}=$ hexanal area in the second desorption. The values obtained were 98.5, 98.8 and 99.0 for fibre positions of 4.0, 4.2 and 4.4, respectively. The 4.4 position yielding the highest desorption percentage was selected, though the differences among the three positions were small.

The 4.4 position was also assayed for pentane with a spiked sample (46.98 ng pentane/ml), and obtaining $99.71 \%$ desorption.

\subsubsection{Equilibration time}

Sample (LH) was equilibrated at $37^{\circ} \mathrm{C}$ for $2,5,10,15$, 30 and $60 \mathrm{~min}$. To improve estimates of the experimental value, assays were performed in duplicate.

After equilibration, the headspace was extracted for $30 \mathrm{~min}\left(37^{\circ} \mathrm{C}\right)$ with the fibre, which was inserted in the $\mathrm{GC}$ injector and analyzed as reported before. The ratio between the chromatographic areas corresponding to the analytes and IS (relative areas), obtained for the assayed equilibration times, are represented in Fig. 1. The increments in relative area indicate that equilibrium between headspace and sample was reached at $30 \mathrm{~min}$ for both hexanal and pentane (see Fig. 1). However, in the case of hexanal, differences in the area ratio between 15 and $30 \mathrm{~min}$ were small (0.02); with $15 \mathrm{~min}$ of equilibration time the ratio of the areas was $92.9 \%$ of the value obtained with 30 min of equilibration - reproducibility being the same, with similar relative standard deviations (RSD) of 3.8\% and $3.6 \%$ at 15 and $30 \mathrm{~min}$, respectively. The small difference in sensitivity, together with the reduction in the time needed for analysis, justified the choice of the time (15 min) for equilibration.

It should be noted that quantitative analysis by SPME is feasible in non-equilibrium situations when the agitation conditions and adsorption time are held constant. A much shorter sampling time can be used for quantitative analysis provided sensitivity is not the main concern ( $\mathrm{Ai}, 1997)$.

(a)

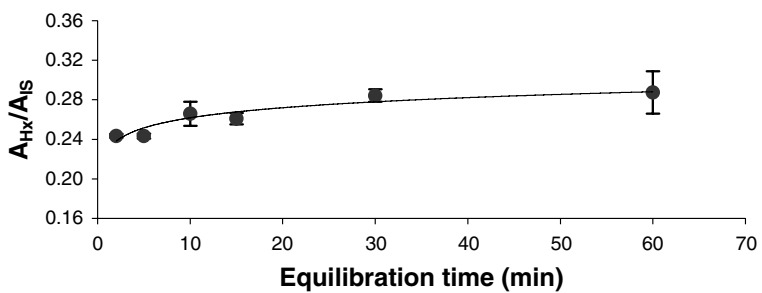

(b)

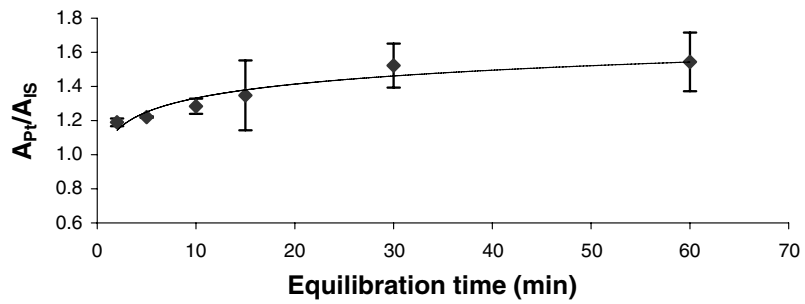

Fig. 1. Equilibration time: obtained after $30 \mathrm{~min}$ sampling at $37^{\circ} \mathrm{C}$. (a) Hexanal: relative areas (hexanal $\left(A_{\mathrm{Hx}}\right) /$ internal standard $\left(A_{\mathrm{IS}}\right)$ and $(\mathrm{b})$ pentane: relative areas (pentane $\left.\left(A_{\mathrm{Pt}}\right) / A_{\mathrm{IS}}\right)$. Average \pm standard deviation. 


\subsubsection{Sampling time}

The SPME fibre was exposed for different times $(5,15$, 30,45 and $60 \mathrm{~min}$ ) to the headspace above an already equilibrated sample $\left(15 \mathrm{~min}\right.$ at $\left.37^{\circ} \mathrm{C}\right)$. The assays were carried out in duplicate. After the exposure time, the compounds adsorbed by the fibre were desorbed in the GC injector. Fig. 2 shows the absolute and relative (analyte/ IS) areas of both analytes.

An increase was observed in the areas corresponding to hexanal with increasing extraction time (see Fig. 2a). However, when the areas were related to the IS, similar responses were obtained for all times assayed (Fig. 2b).

In the case of pentane, the increase in absolute areas was more pronounced with the shorter (5 and $15 \mathrm{~min}$ ) than with the longer assayed times (see Fig. 2c). However, differences between pentane and IS in affinity for the fibre explain the behaviour of the pentane/IS area ratio (Fig. 2d). Given that a better reproducibility of the values was obtained with a 45 min sampling time $(\mathrm{RSD}=0.9 \%)$ than with lower values at $30 \mathrm{~min}(\mathrm{RSD}=9.2 \%)$, a $45 \mathrm{~min}$ extraction time was selected for both hexanal and pentane - taking into account that for pentane a better reproducibility in the response was obtained than with lower sampling times.

The times selected ( $15 \mathrm{~min}$ for equilibration and $45 \mathrm{~min}$ for sampling) allow the entire analysis to be completed in $1.5 \mathrm{~h}$ (15 min equilibration plus $45 \mathrm{~min}$ extraction plus 30 min of GC analysis).

The chromatograms, corresponding to pentane and hexanal from two liquid cereal-milk based infant foods ( $\mathrm{LH}$ and LF) and a powdered adapted milk IF (A) obtained under the mentioned assay conditions are reported in Fig. 3. The peaks of pentane and hexanal were identified by comparing their retention times to those of the standards and also by $\mathrm{GC}-\mathrm{MS}$ analysis.

(a)

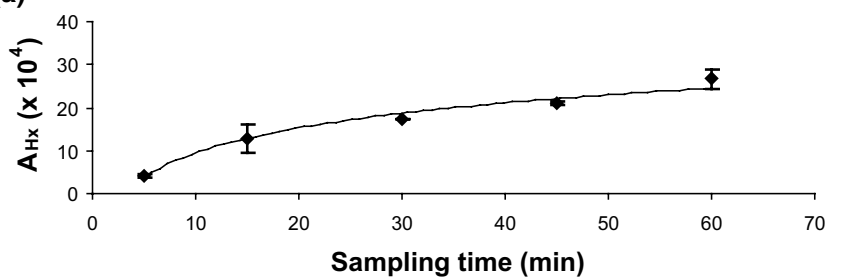

(b)

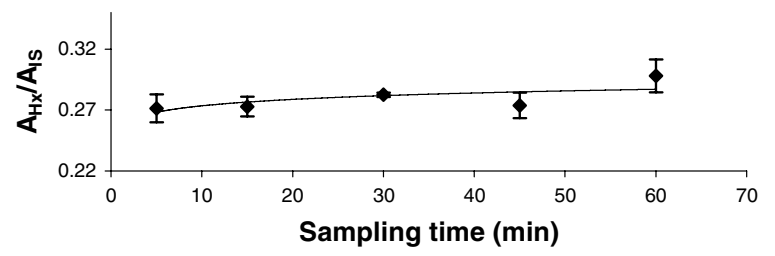

The sample containing fruits (LF) contained a greater number of volatile compounds than those containing honey (LH). In the first (LF) hexanal, which presence was confirmed by SIM, co-eluted with another compound identified as ethylbutanoate. It was not possible to improve the resolution of these peaks, because in columns of the polarity used, the Kovats indexes of hexanal and ethylbutanoate are very similar (802 and 804, respectively) (Adams, 2001). Therefore, under the analytical conditions applied in the present study, hexanal cannot be used as indicator of lipid oxidation in sample LF. In contrast, peak corresponding to pentane could be quantified and, thus, be used to monitor lipid oxidation in it. On the same basis, hexanal and pentane contents can be quantified in sample LH.

\subsection{Validation of the SPME-GC method}

Once the conditions were optimized, the analytical parameters of the method were determined to validate the usefulness of the SPME-GC method for hexanal and pentane determination in stored liquid cereal-based infant foods.

\subsubsection{Linearity}

MIBK was used as IS in the quantification. Calibration curves were obtained with a set of aliquots of liquid infant foods (LH) and (LF) added with increasing amounts of hexanal and pentane and a fixed amount of IS (240 ng). Regression equations and correlation coefficients are reported in Table 2.

\subsubsection{Detection and quantification limits - sensitivity}

The detection and quantification limits of hexanal and pentane, estimated in accordance with American Chemical

(c)

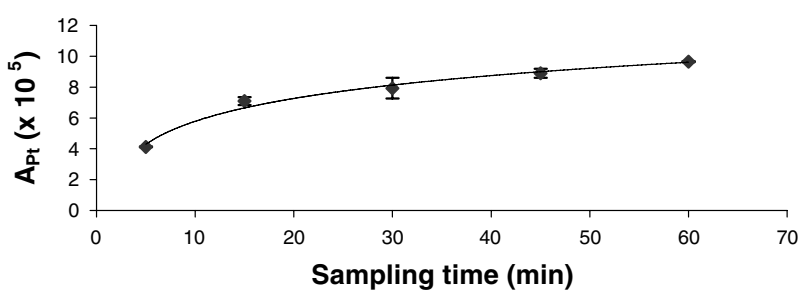

(d)

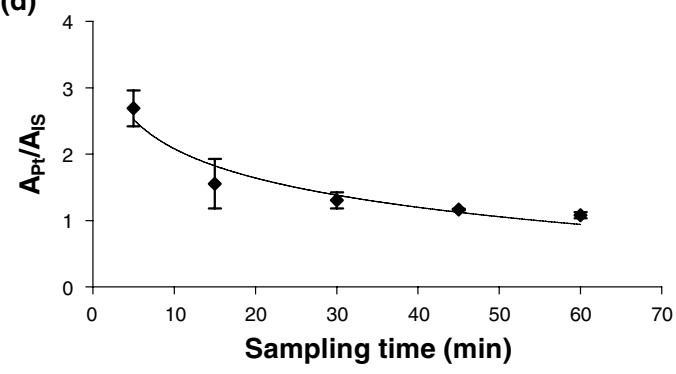

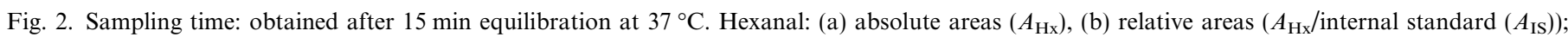
pentane: (c) absolute areas $\left(A_{\mathrm{Pt}}\right)$ and $(\mathrm{d})$ relative areas $\left(A_{\mathrm{Pt}} / A_{\mathrm{IS}}\right)$. Average \pm standard deviation. 
(a)

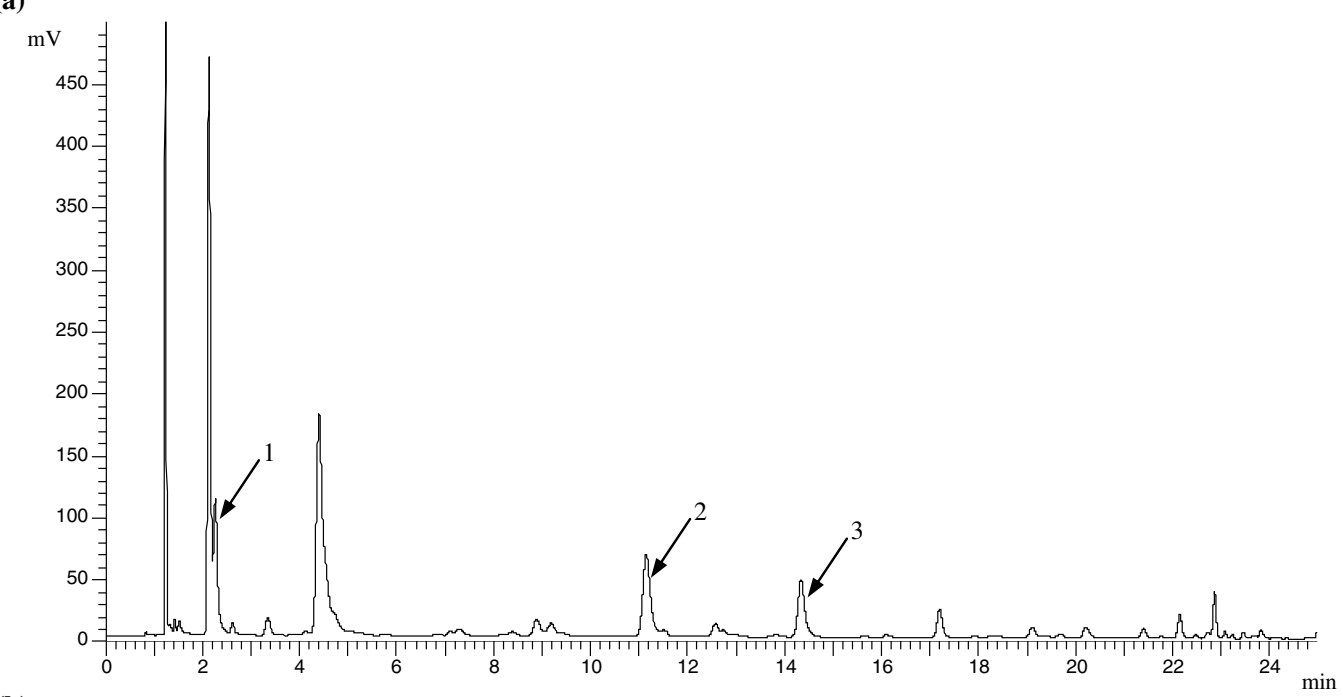

(b)

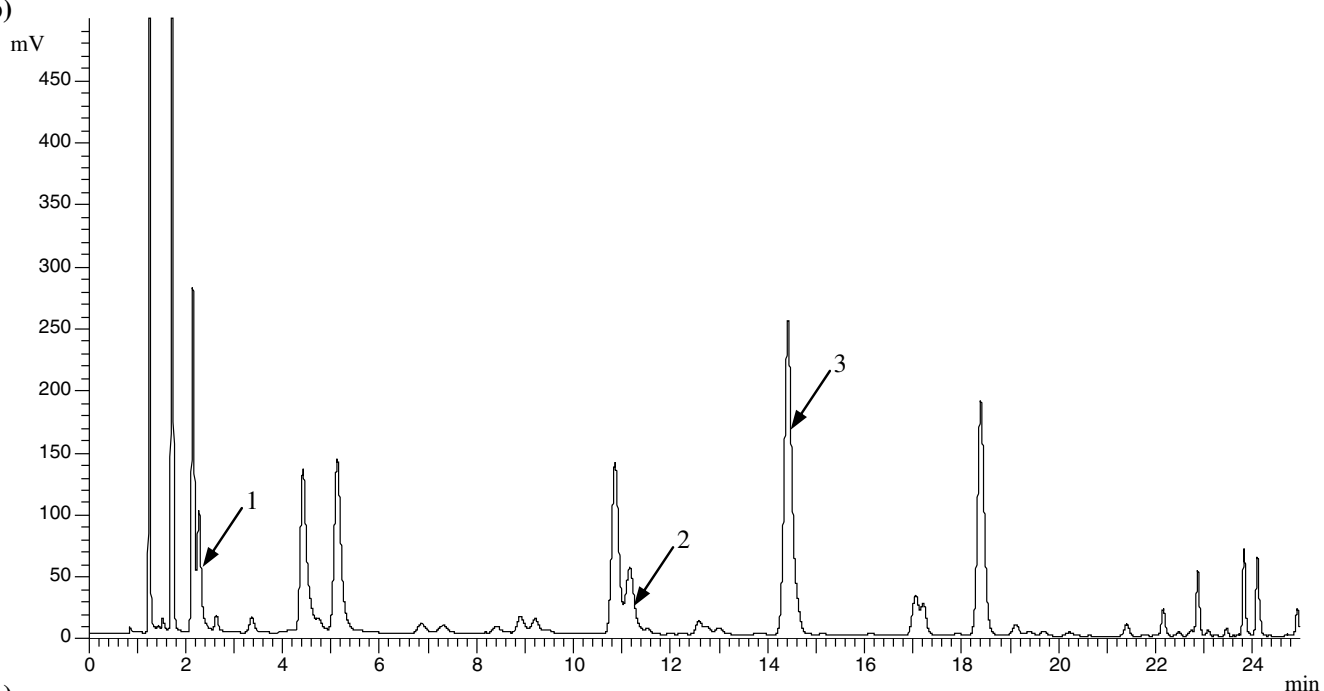

(c)

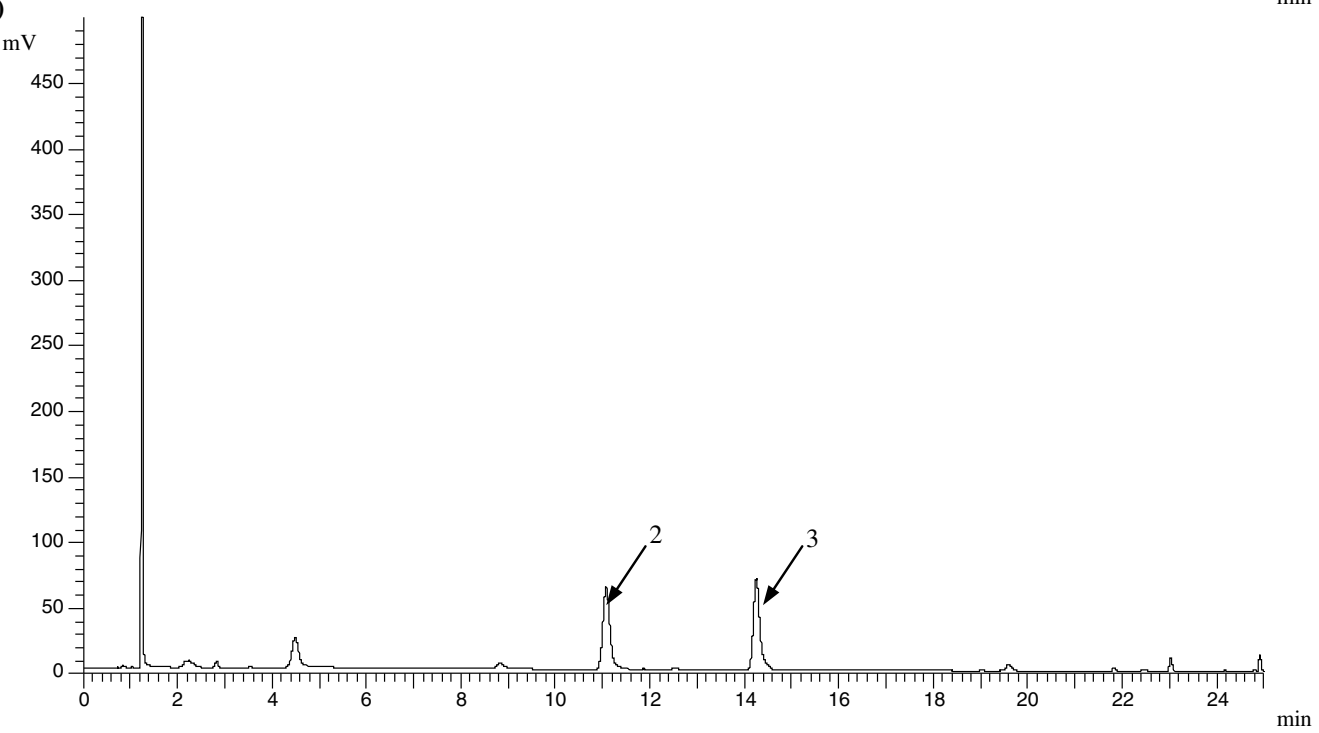

Fig. 3. Hexanal and pentane by HS-SPME-GC-FID: chromatograms of liquid infant foods (a) LH, (b) LF and (c) powdered adapted infant formula A, spiked with internal standard (IS). Peaks numbered correspond to 1, pentane; 2, IS; and 3, hexanal. In chromatogram (b), hexanal (peak 3) coelute with ethylbutanoate. 
Society guidelines (1980) (defined as signal 3 and 10 times the height of the noise level respectively) are reported in Table 3.

The detection limit $(3.6 \mathrm{ng})$ obtained for hexanal was lower than the value (19.6 $\mathrm{ng}$ ) reported for infant formulas by Romeu-Nadal et al. (2004) using a headspace gas chromatographic method, and similar to the limit obtained by Sanches-Silva et al. (2004) for potato crisps using a HSSPME-GC-MS method. No values corresponding to the detection limit for pentane in infant formulas or paps have been reported.

\subsubsection{Precision}

Repeatability expressed as the RSD (relative standard deviation) of relative peak areas of three replicates $(4 \mathrm{ml}$ of liquid infant food) was lower for hexanal $(2.87 \%)$ than for pentane $(3.46 \%)$ in LH sample - with a better RSD obtained for pentane $(2.34 \%)$ in LF sample.

Similar values have been reported for hexanal by Romeu-Nadal et al. (2004) (2.29\%), while Sanches-Silva et al. (2004) documented higher values $(7.56 \%)$.

\subsubsection{Accuracy}

Accuracy was estimated by recovery assays. In the case of hexanal, 5 aliquots of LH sample were spiked with an amount of hexanal (20 ng hexanal/g) equivalent to the hexanal content of the analyzed sample after eight months of storage. The recovery percentage of pentane was obtained by spiking four aliquots of the sample (stored for 5 months) with an amount of pentane $(25 \mathrm{ng} / \mathrm{g})$ corresponding to their content. Recovery percentages of $106.6 \%$ and $95.39 \%$ were obtained for hexanal and pentane, respectively.

\subsection{Application}

Hexanal and/or pentane contents in the analyzed liquid infant foods and powdered IF, stored for four and seven months, are shown in Table 4.

Milk based powdered IF were reconstituted at $0.5 \%(\mathrm{w} / \mathrm{v})$ for analysis, and $4 \mathrm{ml}$ of the resulting liquid/solution was introduced in the 10-ml headspace amber glass vials, together with $240 \mathrm{ng}$ of IS. In these samples no pentane was detected, even when IF were reconstituted at $4 \% \mathrm{w} / \mathrm{v}$. On the other hand, no matrix interferences were detected by the standards additions method; thus, in IF aqueous calibration curves with IS were used for hexanal quantification. The regression equation for hexanal (120-417.2 $\mathrm{ng})$ was: $y=0.0102 x-0.3264, r=0.9989$; where: $y=$ hexanal area/IS area, $x=$ hexanal content (ng), and $r=$ correlation coefficient.

In IF samples, the hexanal contents (see Table 4) are given as $\mathrm{ng} / \mathrm{g}$ powdered formula and also as $\mathrm{ng} / \mathrm{ml}$ of the ready to eat reconstituted formula $(13 \%$, w/v) (see Table 4), to allow comparison between the hexanal contents in IF and in cereal-milk based infant foods.

The values obtained show that in all cases, the hexanal content in IF was higher than in milk-cereal based infant foods. In the latter (milk-cereal based infant foods) with a higher water activity $\left(a_{\mathrm{w}}\right)$ and lower fat content than IF, the presence of pentane and hexanal in similar and relatively low amounts could be explained by the homolytic scission of hydroperoxides yielding hexanal and pentane (Frankel, 1991). In contrast, in IF the low $a_{\mathrm{w}}$ and a fat content of $25 \%(\mathrm{w} / \mathrm{w})$ favour oxidation process, but only hexanal was detected. It should be noted that reconstituted/ ready to eat IF and liquid milk and cereal based products

Table 2

Hexanal $(\mathrm{Hx})$ and pentane $(\mathrm{Pt})$ : linearity

\begin{tabular}{lll}
\hline & Sample LH - hexanal + pentane & Sample LF - pentane \\
\hline Contents range ng/g sample & Hx: $2.48-84.78$ & $19.06-79.98$ \\
& Pt: $6.21-79.55$ & $y=0.026 x+0.671 ;$ \\
Regression equation & Hx: $y=0.025 x+0.568 ; r=0.999$ & $r=0.994$ \\
& Pt: $y=0.031 x+1.002 ; r=0.990$ & $r$ \\
\hline
\end{tabular}

LH, liquid infant food with honey; LF, liquid infant food with fruits; $y=$ analyte area/IS area; $x=$ analyte concentration (ng/g sample); $r=$ least correlation coefficient.

Table 3

Hexanal and pentane: analytical parameters

\begin{tabular}{|c|c|c|c|c|}
\hline & \multicolumn{2}{|l|}{ Hexanal } & \multicolumn{2}{|l|}{ Pentane } \\
\hline & Sample (ng/g) & Assay (ng) & Sample (ng/g) & Assay (ng) \\
\hline Detection limit $(n=3)$ & 0.91 & 3.63 & 1.05 & 4.20 \\
\hline \multirow[t]{2}{*}{ Precision $(n=3) \mathrm{RSD} \%$} & \multirow{2}{*}{\multicolumn{2}{|c|}{2.87 (sample LH) }} & \multirow{2}{*}{\multicolumn{2}{|c|}{$\begin{array}{l}3.46 \text { (sample LH) } \\
2.34 \text { (sample LF) }\end{array}$}} \\
\hline & & & & \\
\hline \multirow[t]{2}{*}{ Recovery \% } & \multicolumn{2}{|c|}{ Present: $24.13 \mathrm{ng} / \mathrm{g}$} & \multicolumn{2}{|c|}{ Present: $26.30 \mathrm{ng} / \mathrm{g}$} \\
\hline & \multicolumn{2}{|c|}{ Spiked: $21.15 \mathrm{ng} / \mathrm{g}$} & \multicolumn{2}{|c|}{ Spiked: $25.25 \mathrm{ng} / \mathrm{g}$} \\
\hline
\end{tabular}

RSD, relative standard deviation; LH, liquid infant food with honey; LF, liquid infant food with fruits. 
Table 4

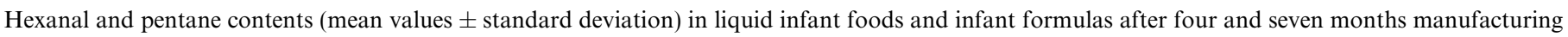

\begin{tabular}{|c|c|c|c|c|}
\hline \multirow[t]{2}{*}{ Sample } & \multirow[t]{2}{*}{ Months } & \multicolumn{2}{|c|}{ Hexanal contents } & \multirow{2}{*}{$\begin{array}{l}\text { Pentane contents } \\
\mathrm{ng} / \mathrm{g}\end{array}$} \\
\hline & & $\mathrm{ng} / \mathrm{g}$ & $\mathrm{ng} / \mathrm{ml}^{\mathrm{a}}$ & \\
\hline \multirow[t]{2}{*}{ LH } & 4 & $22.3 \pm 0.1$ & & $19.6 \pm 2.4$ \\
\hline & 7 & $22 \pm 3$ & & $30.9 \pm 3.6$ \\
\hline \multirow[t]{2}{*}{ LF } & 4 & - & & $34.7 \pm 1.8$ \\
\hline & 7 & - & & $45.5 \pm 3.5$ \\
\hline \multirow[t]{2}{*}{ A } & 4 & $7172.7 \pm 454.2$ & $932.5 \pm 59.1$ & n.d. \\
\hline & 7 & $6074.8 \pm 212.6$ & $789.7 \pm 27.6$ & n.d. \\
\hline \multirow[t]{2}{*}{ Alc } & 4 & $5877.7 \pm 804.6$ & $764.1 \pm 104.6$ & n.d. \\
\hline & 7 & $3482.6 \pm 270.5$ & $452.7 \pm 35.2$ & n.d. \\
\hline \multirow[t]{2}{*}{$\mathrm{Fa}$} & 4 & $2515.2 \pm 135.2$ & $327 \pm 17.6$ & n.d. \\
\hline & 7 & $1017.1 \pm 139.7$ & $132.2 \pm 18.2$ & n.d. \\
\hline \multirow[t]{2}{*}{$\mathrm{Fb}$} & 4 & $4650.8 \pm 627.4$ & $604.6 \pm 81.6$ & n.d. \\
\hline & 7 & $3627.4 \pm 340.5$ & $471.6 \pm 44.3$ & n.d. \\
\hline
\end{tabular}

LH, liquid infant food with honey; LF, liquid infant food with fruits; A, adapted infant formula; Alc, adapted infant formula with long chain polyunsaturated fatty acids added; $\mathrm{Fa}$ and $\mathrm{Fb}$, follow-up infant formulas; n.d., not detectable.

${ }^{\text {a }}$ IF reconstituted at $13 \%(\mathrm{w} / \mathrm{v})$.

have rather similar contents of the precursor linoleic acid (Table 1), the same vitamin E contents $(1 \mathrm{mg} / 100 \mathrm{ml}$ in both types of products) and vitamin $\mathrm{C}$ contents of $6.5 \mathrm{mg} / 100 \mathrm{ml}$ in IF and $9.7 \mathrm{mg} / 100 \mathrm{ml}$ in paps. Although, in the storage conditions IF had higher antioxidant contents than paps and a lower water activity $\left(a_{\mathrm{w}}\right)$ favouring the antioxidant activity. In this sense, Frankel (1991) indicates that $\alpha$-tocopherol (hydrogen donor compound) reduces and increases the relative percentages of pentane and hexanal, respectively.

In support of this observation are the results obtained in a study carried out by Ulberth and Roubicek (1995) in milk powder samples, with a fat content of $26 \%$ and stored for 130 days at $30^{\circ} \mathrm{C}$, where hexanal contents of $106 \mathrm{ng} / \mathrm{g}$ but no pentane were found.

In the ready-to-eat liquid cereal-milk based infant foods no differences in the hexanal contents between the samples stored for four and seven months were found, while in both samples (LH and LF) the pentane contents increased with the storage time. These observations are in agreement with the fact, previously reported, that hexanal unlike pentane can react with other sample components.

It has to be noted that the analyzed liquid infant foods were provided by the manufacturer immediately after the manufacture, so the samples stored for four and seven months came from the same batch and the storage conditions were controlled and the same for both samples ( $\mathrm{LH}$ and LF). While the powdered IF were bought, came from different batches and their storage conditions before the purchase were unknown. The fact that in IF the hexanal contents were lower in samples stored for seven than for four months could at first seem amazing, but one can suspect that the decrease could be due to the reaction of hexanal with other sample components such as the Maillard reaction products, although this assertion can not be categorical, because the differences could also be ascribed to the manufacturing process (two different batches) and also to different storage conditions.
In any case, the described and validated method of hexanal and pentane determination by HS-SPME-GC is useful for monitoring the stability of the lipid fraction in infant foods.

\section{Acknowledgements}

Thanks are due to Hero España S.A. for providing the samples and financial supports for this study, and also to the Generalitat Valenciana for the financial support (03/ 003) given to the "Bionutest group".

\section{References}

Adams, R. P. (2001). Appendix II-Compounds listed in order of their retention time and Kovats index on DB-5. In Identification of essential oil components by gas chromatographylquadrupole mass spectroscopy (pp. 25-40). Carol Stream, IL: Allured Publishing Corporation.

Ai, J. (1997). Solid phase microextraction for quantitative analysis in nonequilibrium situations. Analytical Chemistry, 69, 1230-1236.

American Chemical Society (ACS) Committee on Environmental Improvement (1980). Guidelines for data acquisition and data quality evaluation in environmental chemistry. Analytical Chemistry, 52, 2242-2249.

Arthur, C. L., \& Pawliszyn, J. (1990). Solid phase microextraction with thermal desorption using fused silica optical fibers. Analytical Chemistry, 62, 2145-2148.

Brunton, N. P., Cronin, D. A., Monahan, F. J., \& Durcan, R. (2000). A comparison of solid-phase microextraction (SPME) fibres for measurement of hexanal and pentanal in cooked turkey. Food Chemistry, 68, 339-345.

Buttery, R. G., Turnbaugh, J. G., \& Ling, L. C. (1988). Contribution of volatiles to rice aroma. Journal of Agricultural and Food Chemistry, 36, 1006-1009.

Chung, H.-Y., Partridge, J., Harte, B. (2002). Discrimination of light oxidized off-flavors in milk and cheddar cheese using solid-phase microextraction-gas chromatography and the olfactory sensing technique. In Proceedings of the 13th IAPRI conference on packaging, E. Lansing, Michigan.

Doleschall, F., Kemény, Z., Recseg, K., \& Kovári, K. (2001). Monitoring of lipid degradation products by solid-phase microextraction. Journal of Microcolumn Separations, 13, 215-220.

Doleschall, F., Recseg, K., Kemény, Z., \& Kövári, K. (2003). Comparison of differently coated SPME fibres applied for monitoring volatile 
substances in vegetable oils. European Journal of Lipid Science and Technology, 105, 333-338.

Dupuy, H. P., Flick, G. J., Jr., Bailey, M. E., St. Angelo, A. J., Legendre, M. G., \& Sumrell, G. (1985). Direct sampling capillary gas chromatography of volatiles in vegetable oils. Journal of the American Oil Chemists' Society, 62, 1690-1693.

Fenaille, F., Visani, P., Fumeaux, R., Milo, C., \& Guy, P. A. (2003). Comparison of mass spectrometry-based electronic nose and solid phase microextraction gas chromatography-mass spectrometry technique to assess infant formula oxidation. Journal of Agricultural and Food Chemistry, 51, 2790-2796.

Frankel, E. N. (1980). Lipid oxidation. Progress in Lipid Research, 19, $1-22$.

Frankel, E. N. (1982). Volatile lipid oxidation products. Progress in Lipid Research, 22, 1-33.

Frankel, E. N. (1991). Recent advances in lipid oxidation. Journal of the Science of Food and Agriculture, 54, 495-511.

Frankel, E. N. (1993). Formation of headspace volatiles by thermal decomposition of oxidized fish oils vs. oxidized vegetable oils. Journal of the American Oil Chemists' Society, 70, 767-772.

Frankel, E. N., Neff, W. E., \& Weisleder, D. (1982). Formation of hydroperoxy bis-epidioxides in sensitized photo-oxidized methyl linolenate. Journal of the Chemical Society-Chemical Communications, 599-600.

Frankel, E. N., Hu, M. L., \& Tappel, A. L. (1989). Rapid headspace gas chromatography of hexanal as a measure of lipid peroxidation in biological samples. Lipids, 24, 976-981.

Gianelli, M. P., Flores, M., \& Toldrá, F. (2002). Optimisation of solid phase microextraction (SPME) for the analysis of volatile compounds in dry-cured ham. Journal of the Science of Food and Agriculture, 82, 1703-1709.

Goodridge, C. F., Beaudry, R. M., Pestka, J. J., \& Smith, D. M. (2003). Solid phase microextraction-gas chromatography for quantifying headspace hexanal above freeze-dried chicken myofibrils. Journal of Agricultural and Food Chemistry, 51, 4185-4190.

Jelen, H. H., Wlazly, K., Wasowicz, E., \& Kaminsky, E. (1998). Solidphase microextraction for the analysis of some alcohols and esters in beer: comparison with static headspace method. Journal of Agricultural and Food Chemistry, 46, 1469-1473.

Lagarda, M. J., Máñez, J. G., Manglano, P., \& Farré, R. (2003). Lipid peroxides determination in milk based infant formulae by gas chromatography. European Journal of Lipid Science and Technology, 195, 339-345.

Löliger, J. (1990). Headspace gas analysis of volatile hydrocarbons as a tool for the determination of the state of oxidation of foods stored in sealed containers. Journal of the Science of Food and Agriculture, 52, $119-128$.

Marsili, R. T. (1999). Comparison of solid-phase microextraction and dynamic headspace methods for the gas chromatographic-mass spectrometric analysis of light-induced lipid oxidation products in milk. Journal of Chromatographic Science, 37, 17-23.

Marsili, R. T. (2000). Shelf-life prediction of processed milk by solid-phase microextraction, mass spectrometry, and multivariate analysis. Journal of Agricultural and Food Chemistry, 48, 3470-3475.

Park, P. S. W., \& Goins, R. E. (1992). Determination of volatile lipid oxidation products by dynamic headspace-capillary gas chromatographic analysis with application to milk-based nutritional products. Journal of Agricultural and Food Chemistry, 40, $1581-1585$.

Przygonski, K. (2003). Analysis of volatile lipid oxidation products in infant formula by dynamic-headspace SPME/GC. Prace Instytow $i$ Laboratoriow Badawczych Przemyslu Spozywczego, 58, 86-94.

Robards, K., Kerr, A. F., Patsalides, E., \& Korth, J. (1988). Headspace gas analysis as a measure of rancidity in corn chips. Journal of the American Oil Chemists' Society, 65, 1621-1626.

Romeu-Nadal, M., Castellote, A. I., \& López-Sabater, M. C. (2004). Headspace gas chromatographic method for determining volatile compounds in infant formulas. Journal of Chromatography A, 1046, 235-239.

Sanches-Silva, A., Rodríguez-Bernaldo de Quirós, A., López-Hernández, J., \& Paseiro-Losada, P. (2004). Determination of hexanal as indicator of the lipidic oxidation state in potato crisps using gas chromatography and high-performance liquid chromatography. Journal of Chromatography $A, 1046,75-81$.

Snyder, J. M., Frankel, E. N., Selke, E., \& Warner, K. (1988). Comparison of gas chromatographic methods for volatile lipid oxidation compounds in soybean oil. Journal of the American Oil Chemists' Society, $65,1617-1620$.

Ulberth, F., \& Roubicek, D. (1995). Monitoring of oxidative deterioration of milk powder by headspace gas chromatography. International Dairy Journal, 5, 523-531.

Vichi, S., Pizzale, L., Conte, L. S., Buxaderas, S., \& López-Tamames, E. (2003). Solid-phase microextraction in the analysis of virgin olive oil volatile fraction: characterization of virgin olive oils from two distinct geographical areas of northern Italy. Journal of Agricultural and Food Chemistry, 51, 6572-6577.

Yang, X., \& Peppard, T. (1994). Solid-phase microextraction for flavor analysis. Journal of Agricultural and Food Chemistry, 42, 1925-1930.

Zhang, Z., Yang, M. J., \& Pawliszyn, J. (1994). Solid-phase microextraction. Analytical Chemistry, 66, 844A-853A. 